\title{
Reseña de Geografie de Giovanni Catelli
}

Nora Sforza ${ }^{1}$

Universidad de Buenos Aires

Material original autorizado para su primera publicación en el Journal de Ciencias Sociales, Revista Académica de la Facultad de Ciencias Sociales de la Universidad de Palermo.

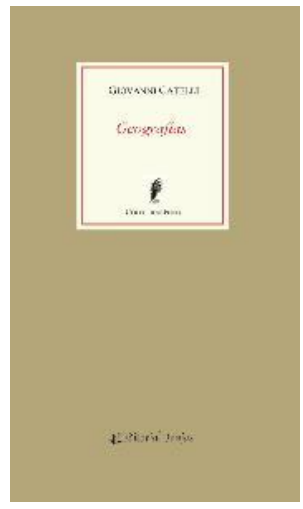

Geografie (2014). Córdoba: Brujas, 156 págs. ISBN: 978-987-591-414-8.

Nacido en Cremona, residente en Crema, habitante sideral de Praga ("vivo en Praga, desde lejos" suele decir), escritor realmente ex-céntrico (en el sentido primordial del término) Giovanni Catelli nos ofrece su tercer libro Geografie, editado por primera vez en su país, por Piero Manni, exquisita editorial de la también exquisita ciudad de Lecce, y publicado el año pasado por primera vez en versión bilingüe, con prólogo del poeta genovés Franco Loi, por la Editorial Brujas de Córdoba con el apoyo del IICórdoba, en la Colección "Fénix", dirigida por el poeta cordobés Pablo Anadón. Anadón, como buen poeta que es, tradujo aquí los 27 pequeños e intensos relatos de Catelli, manteniendo en cada uno de ellos las tensiones, los ritmos, las aceleraciones y desaceleraciones imprevistas que constantemente nos ofrece el texto original. Así, la posibilidad de leer contemporáneamente la versión original y su traducción al italiano constituyen una experiencia vital, que sacude nuestro ser y nos deja indefensos frente a las cuestiones abordadas por Catelli. En efecto, el autor de Geografías, -quien no casualmente ha titulado otros textos suyos con los sugestivos nombres de In fondo alla notte, Partenze, Lontananze y Treni nos coloca en la necesidad de reflexionar acerca del irrefrenable paso del tiempo ("noi non sappiamo quando l'ora trascorre, la nostra funzione si esaurisce" / "Nosotros no sabemos cuando la hora transcurre, nuestra función se agota", leemos en “Continuità"), nos convoca a pensar en personas sin nombre o en los vagos fantasmas de aquéllas, siempre inasibles y distantes, conjurados protagonistas que pueblan los relatos de una o de tantas geografías las

${ }^{1}$ Doctora en Letras, UBA. Maestra Superior en Ciencias Sociales, FLACSO. mail: norsfo@pccp.com.ar 
que, por supuesto, no son aquéllas que pudiéramos encontrar en un atlas o en una pormenorizada guía turística, sino que constituyen un soporte espacial que nos rehuye todo el tiempo, que se diluye frente a nuestra vista cuando nos parece que hemos podido alcanzarlos, espejismos de una realidad que es profundamente metafísica (“i giorni non recano sempre la migliore stagione, quante città sopravvivono nel solo immaginarla, è troppo vasta l'occasione di queste pianure per poterla racchiudere dentro una sola esistenza", nos dirá aún en "Don Giovanni", volviendo inmediatamente nuestra memoria hacia /l filo dell'orizzonte de Antonio Tabucchi, cuando hace decir al protagonista de la novela, Spino, que "il Latinoamerica è piccolo nello spazio di un sogno"). Por diversos motivos, Catelli nos presenta geografías en gran parte inalcanzables, ausentes, lejanas, que nos mantienen en permanente equilibrio inestable, a las cuales no sabemos si podemos o no pertenecer o si, en definitiva, estamos viendo todo desde lo alto, desde otra dimensión. Espacios de ciudades irreconocibles, despersonalizadas (aunque el yo narrante esté allí, siempre presente, como la virgiliana guía que intenta que no nos perdamos) $Y$, en este sentido, no es casual que entre plazas y estaciones que van y vienen, que se pueblan y se vacían, la primera imagen que se nos presenta y permanece a lo largo de muchos relatos sea, justamente, la de la pintura metafísica de Giorgio De Chirico (pienso en L'enigma dell'ora de 1911, o en Piazza d'Italia, de 1938, por citar sólo algunas de sus obras más conocidas). Encontramos la estación, encontramos el andén, encontramos el tren mas, ¿de dónde venimos? ¿dónde estamos? ¿hacia dónde nos dirigimos? Es esto lo que también nos mantiene en permanente ansia: Giovanni impone a sus textos un ritmo apremiante, acelerado, marcado -como si se tratase del repique de un conjunto de instrumentos de percusión- por el uso de las comas que dividen y marcan permanentemente la totalidad del texto y casi se diría que son estos mínimos espacios de separación -aquellos que, por su misma brevedad, no nos dan siquiera el tiempo de reponer el aire- los que nos conducen de un relato a otro, casi a modo de obsesivo leit motiv. Así también, esta prosa laberíntica se acelera y desacelera llevando al lector a tener que acompañar su lectura no sólo con su mente sino con la energía vital de su propio cuerpo.

Son pocos los espacios geográficos realmente "nombrados" a lo largo de los 27 relatos que componen el libro, pero, a pesar de resultar nombrados, no hay nada en sus descripciones que nos recuerden las características que encontraríamos en esas guías turísticas a las que hacíamos referencia: Catelli no aclara que "Aubervilliers" es un suburbio del norte de París en la Ille de France; que "Vodickova" es una concurridísima calle de Praga, que une los barrios de Karol y Wenceslao; que "Hlavni Nadraži” es la estación central de ferrocarril de Praga; que "Telč" es un pequeño pueblo en la actual República Checa, que "Pankrac" es un suburbio al sur de Praga, tan relacionado con la presencia de la cárcel que en el lenguaje cotidiano de los checos se lo nombra como sinónimo de "cárcel". Tal vez sólo "Le Mans" nos recuerda las 
ansias de la carrera y "Sarajevo" la terrible y devastadora deshumanización de esa última guerra lacerante ("il futuro non possiede la saggezza della devastazione, ancora fuggiremo avvinti alla moneta del destino, al sorriso del nemico, basta solo una firma un acconto al profitto della pace, un foglio bianco un assegno sul tessuto di maceria delle vite, ogni popolo difende i benefici del perdono, ma ogni casa sventrata è una promessa, si moltiplica nel futuro il convoglio deserto della vendetta..." /el futuro no posee la sabiduría de las devastaciones, todavía huiremos atados a la moneda del destino, a la sonrisa del enemigo, basta sólo una firma un anticipo en provecho de la paz, una hoja blanca un cheque sobre el tejido de escombros de las vidas, cada pueblo defiende los beneficios del perdón, pero toda casa destrozada es una promesa, se multiplica en el futuro el convoy desierto de la venganza".) Así, la escritura de Catelli delimita el espacio tangible y también el espacio de lo que sucedió para salvarlo de la fatal ruina del olvido.

Giovanni Catelli nació en Cremona. Autor de prosa y de poesia, sus relatos han aparecido en la Nouvelle Revue Francaise, en el Corriere della Sera, en el sitio literario Nazioneindiana, y en las revistas literarias L'Indice, Diario, L'Immaginazione. Entre sus libros publicados recordamos: In fondo alla notte (Solfanelli, 1992), Partenze (Solfanelli, 1994), Geografie (Manni, 1998), Lontananze (Manni, 2003), Treni (Manni, 2008), Camus deve morire (Nutrimenti 2013), Diorama dell'Est (Lavieri 2013).

Geografie, con prefacio de Franco Loi, ha sido traducido al checo, al ruso, al ucraniano y ahora al español, en la edición que estamos comentando. Otros relatos han sido traducidos y publicados en checo, francés, eslovaco, ruso y finlandés. Desde hace más de veinte años, Catelli sigue con vivo interés las transformaciones literarias, históricas y políticas de la Europa oriental y viaja asiduamente a los países del ex bloque soviético. Además, colabora con el Indice dei Libri, la revista praguense Babylon y dirige "Cafè Golem", la página cultural de Eastjournal.net. 